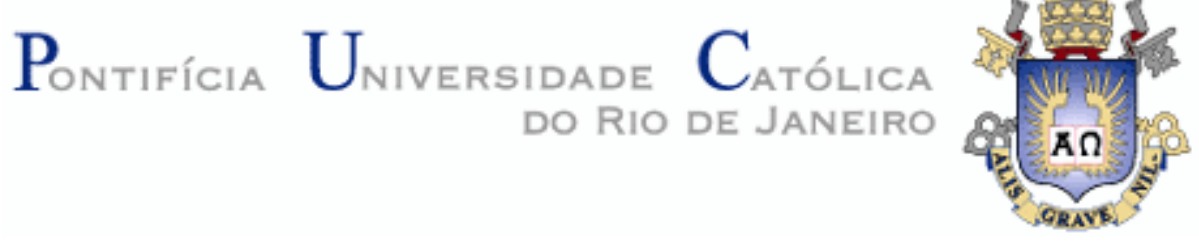

Rafael Bomfim Dutton

\title{
Estratégias e táticas nos trens da Supervia
}

\author{
Dissertação de Mestrado.
}

Dissertação apresentada ao Programa de Pósgraduação em Ciências sociais da PUC-Rio como requisito parcial para obtenção do título de Mestre em Ciências Sociais.

Orientador: Prof. Valter Sinder 


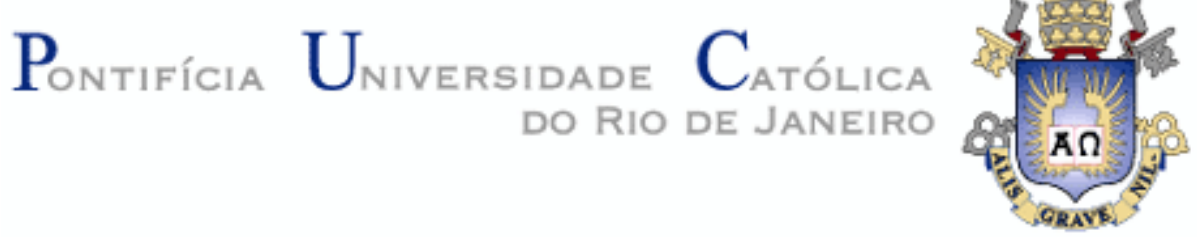

Rafael Bomfim Dutton

\section{Estratégias e táticas nos trens da Supervia}

Dissertação apresentada como requisito parcial para obtenção do título de Mestre pelo Programa de Pós-Graduação em Ciências Sociais da PUCRio. Aprovada pela Comissão Examinadora abaixo assinada.

\section{Prof. Valter Sinder} Orientador

Departamento de Sociologia e Política - PUC-Rio

Prof. Paulo Jorge da Silva Ribeiro Co-Orientador Departamento de Sociologia e Política - PUC-Rio

Prof. João Trajano de Lima Sento-Sé UERJ

Prof. Anderson Moraes de Castro e Silva

INPI

Profa. Mônica Herz Coordenadora Setorial do Centro de Ciências Sociais - PUC-Rio

Rio de Janeiro, 09 de março de 2012 
Todos os direitos reservados. É proibida a reprodução total ou parcial do trabalho sem autorização da universidade, da autora e do orientador.

\section{Rafael Bomfim Dutton}

Graduou-se em História na UFF (2006) e fez mestrado em Ciências Sociais na PUC-Rio. Foi bolsista da FINEP/CNPq no projeto "Gestão escolar e Territórios populares" realizado pelos Departamentos de Sociologia e de Educação da PUC-Rio. Tem interesse nas áreas de Antropologia Urbana, Sociologia urbana e Educação.

Ficha Catalográfica

Dutton, Rafael Bomfim

Estratégias e táticas nos trens da Supervia / Rafael Bomfim Dutton ; orientador: Valter Sinder. 2012.

99 f. : il. (color.) ; $30 \mathrm{~cm}$

Dissertação (mestrado)-Pontifícia Universidade Católica do Rio de Janeiro, Departamento de Sociologia e Política, 2012.

Inclui bibliografia

1. Sociologia - Teses. 2. Trem. 3. Transporte público. 4. Disciplina. I. Sinder, Valter. II. Pontifícia Universidade Católica do Rio de Janeiro. Departamento de Sociologia e Política. III. Título.

CDD: 301 


\section{Agradecimentos}

Aos meus pais, Aída e Edson, por todo amor, apoio e a torcida de sempre durante todo o tempo.

A minha mulher, Mariana Estellita, minha grande companheira e interlocutora, por toda a força que me deu desde a prova de seleção até o último minuto da escrita, me ajudando durante os inúmeros momentos sombrios e compartilhando dos progressos realizados.Além disso, tê-la ao meu lado fez minha vida mais poética e bonita.

Ao professor Valter Sinder, pelas indicações de leituras e pelas palavras de incentivo.

Ao professor Paulo Jorge Ribeiro, pelas valiosíssimas orientações generosamente dadas durante o processo, me fazendo pouco a pouco enxergar questões que estavam além do meu tema.

À professora Maria Isabel Mendes de Almeida, pelas sugestões, indicações bibliográficas e pela leitura cuidadosa e crítica do projeto da qualificação.

Aos membros da banca, pelas grandes contribuições que deram durante a defesa, transformando-a em um momento extremamente enriquecedor.

Ao professor Marcelo Burgos, grande mestre, com quem durante esse tempo trabalhei, pela oportunidade de apreender valiosas lições sociológicas.

Ao corpo docente da Pós-Graduação em Ciências Sociais da Puc-RJ, que me introduziu nas ciências sociais.

Aos alunos da Pós-Graduação em Ciências Sociais, especialmente Jonas Lanna, Olívia Hirsch, Débora Minuzzo (in memoriam), Tatiana Di Sabbato, Daniele Ferreira e Antonio Engelke, pelas inúmeras conversas entre os almoços, os muitos cafezinhos e as poucas cervejas, que ajudaram a descontrair as pressões do mundo acadêmico.

A todos aqueles que de alguma forma me ajudaram durante esta viagem. 


\section{Resumo}

Dutton, Rafael Bomfim; Sinder, Valter. Estratégias e táticas nos trens da Supervia. Rio de Janeiro, 2012. 99p. Dissertação de Mestrado Departamento de Sociologia e Política, Pontifícia Universidade Católica do Rio de Janeiro.

O presente trabalho discute o uso dos trens no Rio de Janeiro e, com o recurso da etnografia, enfoca alguns fenômenos que caracterizam a relação do usuário com o sistema de transporte ferroviário. Este, como todo espaço público, possui um conjunto de regras implícitas e explícitas que permeiam sua relação com o usuário. A partir das teorias de Michel Foucault e Michel de Certeau, são discutidas as tensões entre as "normas disciplinadoras" da empresa Supervia (a concessionária deste serviço) e as "táticas" empreendidas pelos usuários para enfrentá-las.

\section{Palavras-chave}

Trem; transporte público; disciplina. 


\section{Abstract}

Dutton, Rafael Bomfim; Sinder, Valter. (Advisor). Strategies and tatics at Supervia's rail. Rio de Janeiro, 2012. 99p. MSc. Dissertation. Departamento de Sociologia e Política, Pontifícia Universidade Católica do Rio de Janeiro.

The following work discuss about the use of the train commuters in Rio de Janeiro, and by ethnografy resources focuses some phenomenons wich caracterise the relationship of the users to this transport. As every public space, it has oficial and unoficial rules wich permeal the relationship with the users. From Michel Foucaut and Michel de Certeau theories, are discussed the stratch between the "disciplinary rules" of Supervia Company (concessionary of that service) and the "tactics" used by the users to go aganist it.

\section{Keywords}

Strategies and tatics at Supervia's rail. 


\section{Sumário}

$\begin{array}{ll}\text { 1. Introdução } & 10\end{array}$

2. Os transportes no Rio de Janeiro: um breve histórico 15

2.1. O bonde 18

2.2. O trem 19

2.3. O processo de deterioração do transporte ferroviário 28

$\begin{array}{ll}\text { 2.4. As gestões da ferrovia } & 29\end{array}$

2.5. Algumas informações sobre os trens 30

2.5.1. Os tipos de trem 31

2.5.2. O usuário 32

3. O ambiente ferroviário atual 34

3.1. A Estação 36

3.2. Os horários das composições $\quad 37$

3.2.1 Falhas na comunicação e atrasos 39

3.2.2. Os atrasos na Central 41

3.2.3. A corrida 43

3.3. Trem do Samba $\quad 47$

3.4. Os camelôs $\quad 51$

3.5. Pedintes $\quad 54$

3.6. Praia no Trem 56

3.7. Embarcando no Trem 59

3.8. Tática e Estratégia 62

4. Projeto Disciplinador da Supervia 65

4.1. A hipertrofia do poder punitivo da Supervia 70

4.2. A repressão $\quad 75$

4.2.1. O Batalhão de Polícia Ferroviária 76

$\begin{array}{ll}\text { 4.2.2. Os vigilantes } & 78\end{array}$

4.3. O episódio das "chicotadas" 85

4.4. A mordida 86

4.5. O "empata-porta" $\quad 87$

4.5.1. "Não aceite o empata-portas" 91

5. Considerações Finais 95

6. Referências Bibliográficas 96 


\section{Lista de figuras}

Figura 1: Foto da tabela de horário das composições da Estação Mangueira (2012)

Figura 2: Foto de um quadro com avisos da Estação São Cristóvão (2012)

Figura 3: Foto de painel eletrônico com horário das composições na Estação Central do Brasil. Observar a grafia de "suspença" (2011)

Figura 4: Foto do interior de uma composição do ramal Campo Grande (2012)

Figura 5: Cartaz da 1ª campanha do "empata-porta" (Maio. 2010)

Figura 6: Cartaz da 2a campanha do "empata-porta" (Dezembro. 2011) 


\section{Lista de tabelas}

Tabela 1: Volume de passageiros no sistema de trens suburbanos da E.F.C. B (1866-1910)

Tabela 2: Distribuição dos usuários dos trens de acordo com as classes sociais. (Pesquisa realizada pelo IBOPE encomendada pela Supervia, em 2010)

Tabela 3: Faixa etária dos usuários da Supervia. (março. 2010) 